\title{
Catalysis with Complexes Containing Stereogenic Metal Centers"
}

\author{
E. Peter Kündig*
}

\begin{abstract}
Alfred Werner, one of the founders of the Swiss Chemical Society and its first president and the first Nobel Prizewinner for Chemistry in Switzerland, established the stereochemistry of coordination complexes. As an important element in the verification of his hypothesis he demonstrated the existence of two enantiomeric forms of [Co(ethylenediamine) $\left.{ }_{3}\right]\left[\mathrm{Cl}_{3}\right]$. The present article briefly examines the question of the use in asymmetric catalysis of catalysts possessing a stereogenic metal center.
\end{abstract}

Keywords: Stereogenic metal center · Werner, Alfred

\section{Alfred Werner and the Swiss Chemical Society}

The Swiss Chemical Society (SCS) was founded in Zofingen on August 6, 1901 as an independent society within the 'Schweizerische Naturforschende Gesellschaft' (today: Swiss Academy of Sciences). The three members of the SCS Executive Board 1901 were Profs. Alfred Werner (University of Zurich, President), Otto Billeter (University of Neuchâtel, Vice President), and Prof. Amé Pictet (University of Geneva, Secretary and Treasurer) (Fig. 1). [1]

\section{Coordination Number and Stereochemistry of Transition Metal Complexes}

In his article in 1893 entitled 'Contributions to the Constitution of Inorganic Compounds', Werner laid the foundation to stereochemistry of coordination compounds. ${ }^{[2]}$ Breaking with the belief that valency (derived from the oxidation number) and coordination number must be identical, Werner introduced the concept of primary- (Hauptvalenz) and secondary valency (Nebenvalenz) and associated coordination numbers and -geometries with the latter. Thus, close to 20 years after van't

${ }^{*}$ Correspondence: Prof. Dr. E. P. Kündig

President Swiss Chemical Society

Department of Organic Chemistry

University of Geneva

30 Quai Ernest Ansermet

$\mathrm{CH}-1211$ Geneva 4

Tel.: + 41223796093

E-mail: peter.kundig@unige.ch

\#Based on the author's lecture at the University of

Zurich (Nov. 22, 2013) at a one-day symposium commemorating the 100th anniversary of the Nobel Prize in Chemistry for Alfred Werner
Hoff's and Le Bel's formulation of tetrahedral stereochemistry for carbon (Fig. 2), Werner formulated stereochemistry for coordination compounds and broke radically with the heretofore dominant "chain struc-

ture' formulation (Fig. 3). In the following years, Werner focused his research on enlarging this new concept and providing experimental evidence. An important piece of evidence was the isolation of the two

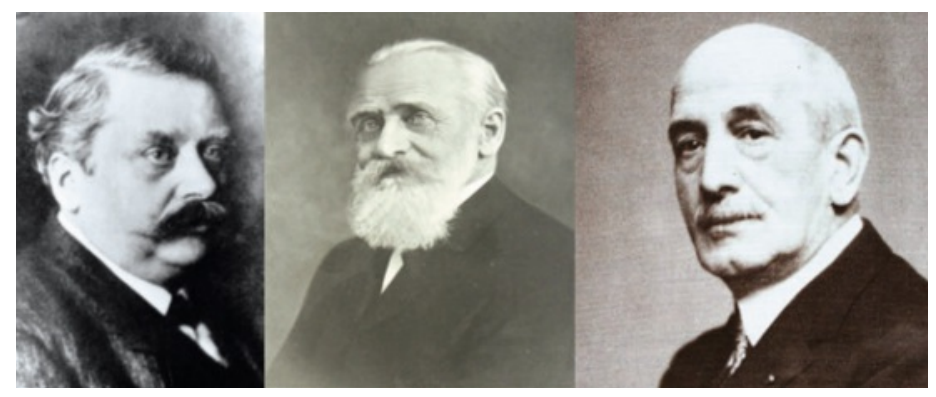

Fig. 1. The three members of the first Swiss Chemical Society Executive Board (1901): Profs. Alfred Werner (left, University of Zurich, President), Otto Billeter (center, University of Neuchâtel, Vice President), and Prof. Amé Pictet (right, University of Geneva, Secretary and Treasurer).
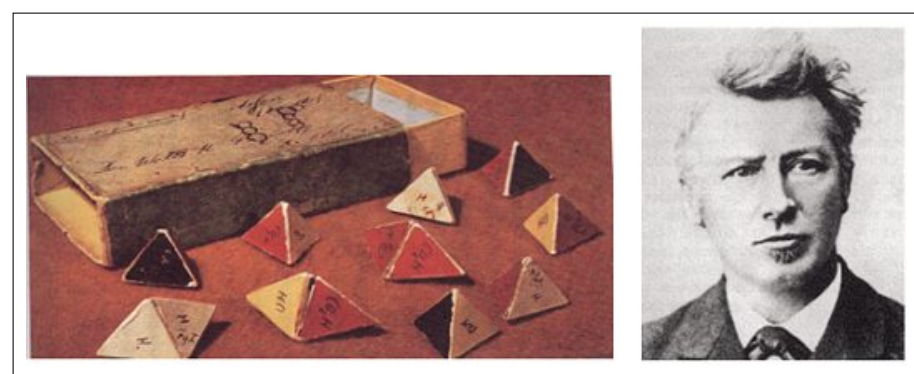

Fig. 2. The discoverers of stereochemistry - tetrahedral carbon (1874). 

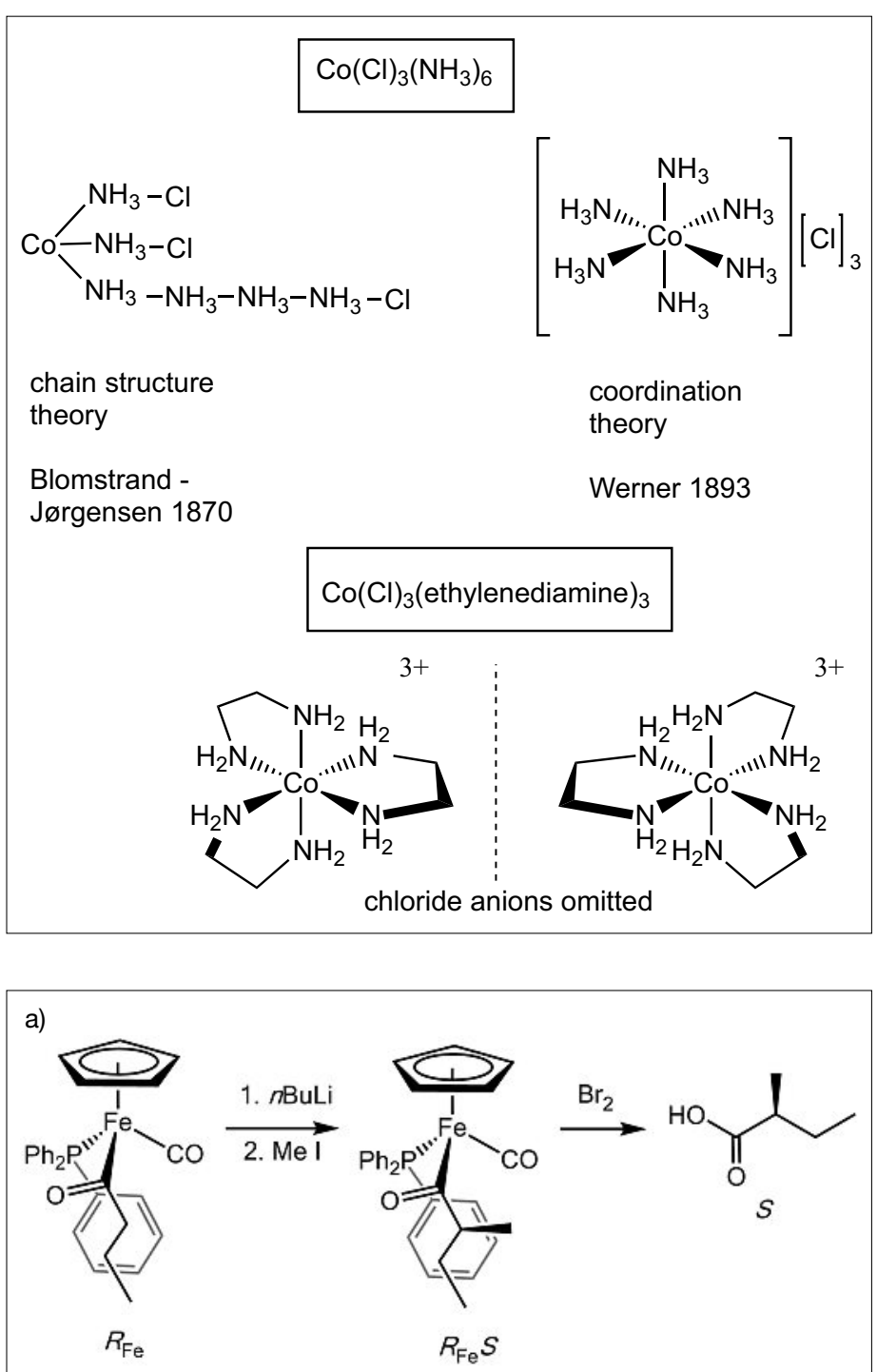

b)
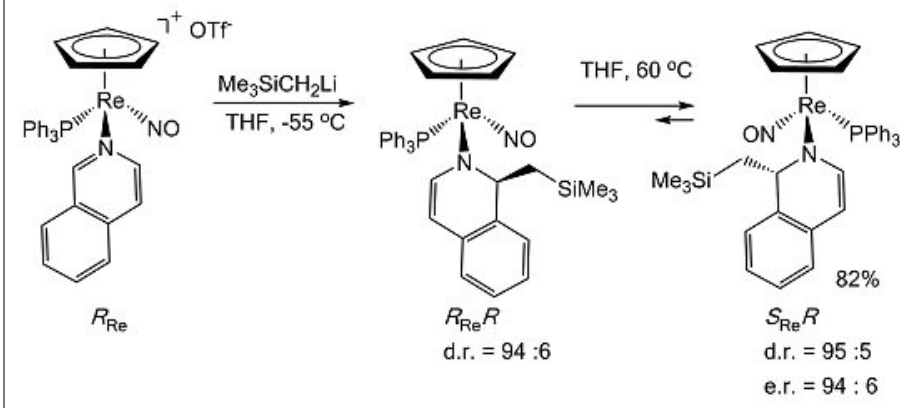

enantiomeric $\left.[\mathrm{Co} \text { (ethylenediamine })_{3}\right]\left[\mathrm{Cl}_{3}\right]$ complexes (Fig. 3). [3] Werner's research led to his being the first Swiss recipient of a Nobel Prize in Chemistry (1913). In this lecture we will not examine further Alfred Werner's life and achievements ${ }^{[4]}$ but briefly examine the question of catalysis with complexes containing stereogenic metal centers. [5]

\section{Complexes Containing Stereogenic Metal Centers}

Metal complexes that are chiral on account of a stereogenic metal center have
Fig. 3. Stereochemistry of $\mathrm{Co}($ III) complexes.

Scheme 1.

Diastereoselective stoichiometric transformations of chiral pseudotetrahedral complexes: a) enolate alkylation, ${ }^{6 \mathrm{6a}} \mathrm{b}$ ) nucleophilic addition followed by epimerization at Re.[6b]

raised wide interest in the organometallic community. We take as example cyclopentadienyl complexes containing three different coligands. These are octahedral structures with three facial coordination sites being taken up by the cyclopentadienyl ligand. They are often called 'pseudotetrahedral' on account of the four bonds even though the angles between the coligands are $90^{\circ}$ and not $109.5^{\circ}$. Chirality denominators using the CIP nomenclature are based on a four-fold coordinated metal center with the $\mathrm{Cp}$ ligand being treated as pseudo-atom of weight 60 . Some of these complexes are configurationally stable and have been used successfully in highly dia- stereoselective stoichiometric reactions. Selected examples are shown in Scheme 1.6] Many complexes of this family undergo racemization via ligand dissociation and this precludes their use in asymmetric catalysis. ${ }^{[7,8]}$ It is different, however if the complexes are diastereomers, that is, if in addition to the stereogenic metal center, they incorporate a chiral ligand. High asymmetric induction with these catalysts can then arise either from a single diastereoisomer present or from a diastereomeric mixture in which one of the diastereoisomers exhibits a much higher reactivity. A small selection of examples are shown in Scheme 2. ${ }^{[9-11]}$ Remarkably, in the ringclosing metathesis reaction both the $S_{\mathrm{Mo}} R$ and the $R_{\mathrm{Mo}} R$ diastereomers afforded the product with the same absolute configuration. In the presence of ethylene which is generated in the reaction, the Mo center undergoes rapid inversion during the reaction. ${ }^{[11 b]}$

When considering a tetradentate ligand such as an ONNO ligand, three different geometries are possible in an octahedral environment (Fig. 4). The trans structure is achiral. The ligand used in the highly asymmetric Jacobsen-Katsuki epoxidation adopts this geometry. ${ }^{[12]}$ Chirality in this case does not arise from a stereogenic metal center but from the $C_{2}$ chirality of the salen type ligand. The tetradentate chiral ONNO ligand TBOx on the other hand enforces a $c i s-\beta$ metal coordination via ligand chirality. As shown by two examples in Scheme 3, the combination of ligand chirality and a stereogenic metal center provides for a very efficient catalyst.[13]

Asymmetric catalysis with metal complexes that derive their chirality exclusively from a stereogenic metal center is rare. This may be because many complexes lack the robustness to keep configurational integrity at high turn-over numbers. Another reason is access. Diastereomer separation is the foremost method for resolution of complexes with stereogenic metal centers and this can be tedious. Nevertheless a number of reports show that the concept is viable and that both level of asymmetric induction and high turnover numbers can be realized. ${ }^{[14]}$ We choose here the reaction shown in Scheme 4. ${ }^{[15]}$ Catalysis does not take place at the stereogenic metal center in this transformation but it is the chiral structure of the complex that leads to asymmetric induction. The authors propose the $\Lambda$-Ir catalyst to act as a template via hydrogen-bonded nitroalkene, and indole to lead to the transition state and on to the product.[15]

In parallel with further advances in chiral ligand development it is highly likely that stereogenic at metal catalysts will gain importance. 

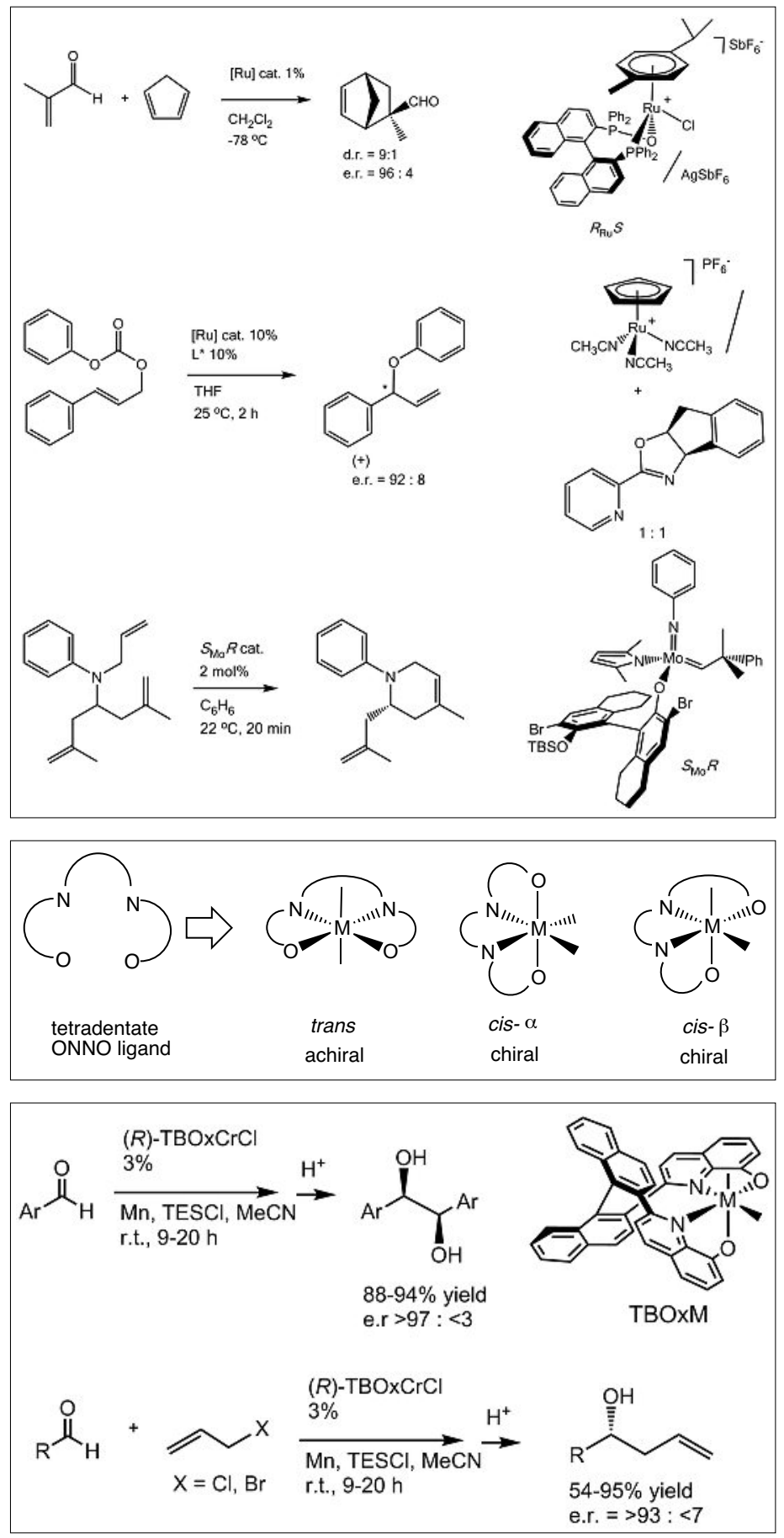

Scheme 3.

Asymmetric catalysis with $\mathrm{TBO} \mathrm{CrCl}$ complexes (cis- $\beta$ coordination). $[13]$

Scheme 2.

Asymmetric catalysis with stereogenic at corporating a chiral ligand. Top: Diels Alder cycloaddition, $[9$ center: decarboxylaetherification, ${ }^{[10}$ ottom: ring-closing metathesis. [11]

Fig. 4. Chiral- and achiral complexes with tetradentate ligands.

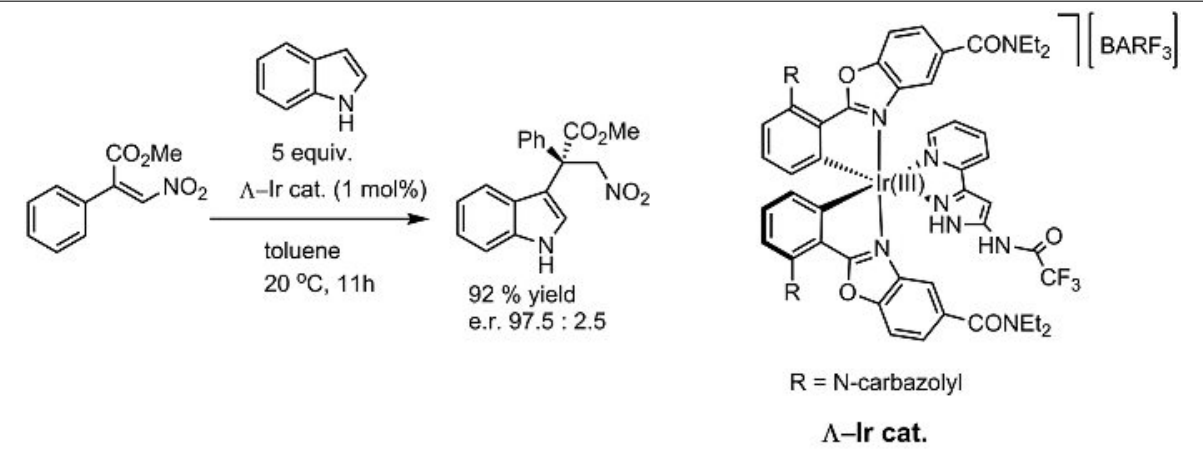

Scheme 4. A stereogenic at iridium complex as template catalyst for the asymmetric construction of an all-carbon quaternary stereocenter. ${ }^{[15]}$

\section{Acknowledgements}

We gratefully acknowledge the University of Zurich and Prof. Roger Alberto for the organization of the one-day symposium (Nov 24, 